\title{
Work related musculoskeletal disorders and ergonomic stressors in the South African workforce
}

\author{
G H Schierhout, J E Meyers, R S Bridger
}

\begin{abstract}
Objectives-The main objective of this study was to investigate exposureresponse relations between adverse musculoskeletal outcomes and ergonomic exposure variables.
\end{abstract}

Methods-A cross sectional analytical study was conducted in 11 factories from seven sectors of manufacturing industry in South Africa. Exposure to workplace ergonomic stressors was assessed in factory floor jobs $(n=46)$ with a simple low technology observational model. Repetition, force, static posture, dynamic movement, and other job exposures were measured. Data of adverse musculoskeletal outcome and data on potential confounders and effect modifiers were obtained from subjects $(n=401)$ randomly sampled from each job category with a questionnaire given by interviewers.

Results-High prevalences of regional musculoskeletal pain were found with substantial variability between industries. Sex was the only individual risk factor (after adjustment for potential confounders and effect modifiers) that was significantly associated with regional pain. Ergonomic exposures in the workplace were significantly associated with musculoskeletal pain of the neck and shoulders odds ratio (OR) $5 \cdot 38$ (95\% confidence interval $(95 \%$ CI) 1.16 to $25 \cdot 0)$ for repetition, and OR $3.91(95 \%$ CI 1.11 to 13.7) for seated compared with standing work; pain of the wrists and hands $O R$ $10.2(95 \%$ CI 1.39 to 75.6$)$ for high summed score of dynamic postures of the wrist).

Conclusions-This study indicates good predictive ability to reduce ergonomic stress with the exposure model, simple surveillance methods, and educational programmes in the workplace. Further study on sampling strategies and refinement of dimensions of ergonomic stressors are needed.

(Occup Environ Med 1995;52:46-50)

Keywords: work related musculoskeletal disorders; ergonomic stressors; epidemiology

A previously published study reported interim findings. ${ }^{\prime}$ Our present paper describes the full. study population and further investigations, which previously were limited by sample size.

The role of ergonomic factors of the workplace in the development of regional musculoskeletal disorders has been a topic of considerable interest and debate in recent years. Exposure-effect relations have been suggested by numerous cross sectional studies in the scientific literature that showed different prevalences of musculoskeletal disozders for different occupations, in conjunction with related biomechanical and physiological principles. Given the multifactorial aetiology and high background prevalence of these disorders, studies that investigate both exposure and outcome are necessary to disentangle occupational and other causes, and to identify appropriate preventive strategies. Few existing studies have adequately characterised ergonomic exposure-either exposure measures are not included at all (other than job title), imprecise exposure measures are used, or insufficient exposure factors or dimensions are included. ${ }^{23}$ Where studies have been able to show exposure-effect relations, the strongest relations were found with self reports of both exposure and outcome. These may lead to overreporting which may artificially inflate associations. Observational models are underused in epidemiological studies. Such methods include a broad spectrum of exposure factors, can be used in large populations, and arguably have considerable potential to reduce bias and misclassification of exposure. This is the first comprehensive study to develop and use a simple low technology observational model to measure ergonomic exposure to show the effects on musculoskeletal health of exposure to workplace ergonomic stressors in a broad range of industrial occupations. This study is also unusual as it was conducted in an underdeveloped country, which needed particular adaptation of study design and methods of measurement.

\section{Subjects and methods}

SELECTION OF OCCUPATIONS

A cross sectional analytical study was conducted in factories drawn from labour intensive industries (excluding mining) in South Africa. Selective sampling, on an invitationresponse basis was used to obtain a spread of factories for participation $(n=11)$ across various industrial sectors. Within each factory, the jobs (or exposure zones, $n=46$ ) 
Table 1 Purticipants by sex and industry (N = size of group; $n=$ number sampled)

\begin{tabular}{|c|c|c|c|c|}
\hline Factory & Occupation & $\operatorname{Sex}$ & $n$ & $N$ \\
\hline Clothiug factory (I) & $\begin{array}{l}\text { Machinist } \\
\text { Ironer }\end{array}$ & $\mathbf{F}$ & $\begin{array}{l}13 \\
04\end{array}$ & $\begin{array}{l}44 \\
04\end{array}$ \\
\hline \multirow[t]{5}{*}{ Clothing factory (II) } & Ironer & $\mathbf{F}$ & 09 & 16 \\
\hline & Machinist & $\mathbf{F}$ & 10 & 26 \\
\hline & Sorter & $\mathbf{F}$ & 05 & 05 \\
\hline & $\begin{array}{l}\text { Examiner } \\
\text { Cutter }\end{array}$ & $\mathbf{F}$ & 06 & 06 \\
\hline & $\begin{array}{l}\text { Cutter } \\
\text { Marker }\end{array}$ & $\mathrm{F}$ & $\begin{array}{l}03 \\
07\end{array}$ & 11 \\
\hline \multirow[t]{2}{*}{ Nylon spinning } & Operator 1 & $\mathbf{M}$ & 09 & 17 \\
\hline & $\begin{array}{l}\text { Operator } 2 \\
\text { Operator } 3\end{array}$ & $M$ & $\begin{array}{l}09 \\
09\end{array}$ & 18 \\
\hline \multirow{5}{*}{ Motor assembly plant } & Spraypainter & $M$ & $\begin{array}{l}09 \\
14\end{array}$ & $\begin{array}{l}18 \\
86\end{array}$ \\
\hline & Assembler 1 & $M$ & 09 & $\begin{array}{l}80 \\
16\end{array}$ \\
\hline & Assembler 2 & M & 12 & 690 \\
\hline & Machinist & $F$ & 14 & 56 \\
\hline & $\begin{array}{l}\text { Spotweld } 1 \\
\text { Spotweld } 2\end{array}$ & $\mathrm{~F}$ & 12 & 244 \\
\hline \multirow{2}{*}{ Metal products } & Mechanic 1 & $\mathrm{M}$ & 14 & $\begin{array}{l}11 \\
50\end{array}$ \\
\hline & Mechanic 2 & $\mathrm{~F}$ & 05 & 6 \\
\hline \multirow{5}{*}{ Chicken processing } & Filleter & $\mathrm{F}$ & 08 & 14 \\
\hline & Cutter & $\mathbf{F}$ & 08 & 13 \\
\hline & Packer & $\mathbf{F}$ & 10 & 24 \\
\hline & Sealer & $\mathbf{F}$ & 07 & 11 \\
\hline & Hanger & $\mathbf{F}$ & 07 & 10 \\
\hline \multirow{3}{*}{ Fruit growers } & Sorter & $\mathbf{F}$ & 11 & 35 \\
\hline & Packer & $\mathbf{F}$ & 16 & 70 \\
\hline & Box maker & $\mathbf{M}$ & 07 & 11 \\
\hline \multirow{6}{*}{ Canning factory } & Line feed & $\mathbf{M}$ & 08 & 14 \\
\hline & Packer 1 & $\mathbf{M}$ & 12 & 40 \\
\hline & Line work & $\mathbf{M}$ & 07 & 11 \\
\hline & Line work & $\mathrm{F}$ & 04 & 04 \\
\hline & $\begin{array}{l}\text { Can maker } \\
\text { Quality }\end{array}$ & $\begin{array}{l}\mathrm{M} \\
\mathrm{F}\end{array}$ & $\begin{array}{l}06 \\
12\end{array}$ & $\begin{array}{l}08 \\
44\end{array}$ \\
\hline & Clerk & $\mathrm{M}$ & 06 & $\begin{array}{l}44 \\
06\end{array}$ \\
\hline \multirow[t]{4}{*}{ Food production } & Operator & $M$ & 14 & 51 \\
\hline & Cleaner & $M$ & 04 & 04 \\
\hline & Mechanic & 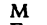 & 05 & 05 \\
\hline & Packer & $\mathbf{F}$ & 08 & 14 \\
\hline \multirow[t]{4}{*}{ Crisp factory } & $\begin{array}{l}\text { Operator } 1 \\
\text { Operator } 2\end{array}$ & $\begin{array}{l}\mathrm{M} \\
\mathrm{F}\end{array}$ & $\begin{array}{l}04 \\
07\end{array}$ & 04 \\
\hline & $\begin{array}{l}\text { Operator } 2 \\
\text { Packer }\end{array}$ & $\mathrm{F}$ & 16 & $\begin{array}{l}11 \\
54\end{array}$ \\
\hline & Box maker & $\mathrm{M}$ & 04 & 04 \\
\hline & Box sealer & $\mathbf{F}$ & 07 & 07 \\
\hline \multirow{3}{*}{$\begin{array}{l}\text { Pharmaceutical } \\
\text { factory }\end{array}$} & Operator & $\mathbf{M}$ & 07 & 11 \\
\hline & Stacker & $\mathbf{M}$ & 12 & 12 \\
\hline & Forklift & $\mathbf{M}$ & 09 & 18 \\
\hline Total & & & 401 & 1839 \\
\hline
\end{tabular}

were sampled from the available factory floor jobs only; administrative, management, and off-floor maintenance occupations were excluded. This sampling strategy aimed to produce a range of exposures. Exposure zones were identified and defined by the researcher according to both the consistency of tasks performed and the similarity of tools, materials, and equipment used by workers within that zone. Where men and women performed the same job, for the purpose of sampling, the job was regarded as two separate exposure zones (for example, packer $M$ and packer $F$ ).

\section{MEASUREMENT OF EXPOSURE}

Exposure was measured with an observational model developed for this purpose. The instrument assessed items of unnatural postures, repeated movements, and force requirements, as well as potential confounders and effect modifiers such as mental concentration demands, temperature extremes, piece rate work, rest pauses, manual handling of materi-

Table 2 Overall mean prevalence of regional pain

\begin{tabular}{llll} 
Pain & $\begin{array}{l}\text { Neck and shoulder } \\
(95 \% C I)\end{array}$ & $\begin{array}{l}\text { Back } \\
(95 \% C I)\end{array}$ & $\begin{array}{l}\text { Forearm, wrist } \\
\text { and hand } \\
(95 \% C I)\end{array}$ \\
\hline Acute & $\begin{array}{l}0.14(0.106 \text { to } 0.174) \\
\text { Chronic }\end{array}$ & $\begin{array}{l}0.20(0.161 \text { to } 0.239) \\
0.194(0.192 \text { to } 0.228)\end{array}$ & $\begin{array}{l}0.02(0.006 \text { to } 0.034) \\
0.04(0.021 \text { to } 0.059)\end{array}$ \\
\hline
\end{tabular}

als and vibration. Items were rated either on a 1-4 scale according to the percentage of the working day spent in that activity-for example, each unnatural posture or movement, materials handled manually and force required-or as present or absent-all other confounders and effect modifiers. Repetition was assessed with cycle time criteria. Postures and repeated movements were summed to form regional scores for different anatomical regions. The method of measurement for each dimension of exposure was derived from adaptations to previously published observational and scoring methods for different exposure variables. ${ }^{4}$

For reasons of capacity and cost-effectiveness, exposure data were recorded for a single subject in each job category $(n=46)$ and exposure was considered to be homogenous within that job category. Previous assessment of validity supported the use of this method in the constrained and repetitive occupations common in labour intensive industries. ${ }^{1}$ All dimensions of exposure in all of the fob categories were measured by a single observer (GS).

\section{SELECTION OF SUBJECTS}

The workers $(n=401)$ were randomly sampled from each exposure zone $(n=46)$ to be given the questionnaire by the interviewer. Workers were sampled from those people present on the days of the interviews, absentees were excluded. Sample size for each occupation was decided in advance to be $95 \%$ sure of obtaining at least one subject in the top $20 \%$ of exposures. ${ }^{5}$

\section{OUTCOME MEASUREMENT}

Subjects were interviewed in their native tongue by interviewers blinded to exposure by the use of an earlier-piloted interviewerquestionnaire. The questionnaire had questions on demographic details, extramural activities, medical and employment history, and musculoskeletal pain (recorded on body diagrams), which included severity and frequency of pain. The questionnaire allowed pain to be reported at multiple sites. Our case definition included only people whose symptoms had developed since working in the current job (after the method of Silverstein et $a l^{6}$ ).

\section{MANAGEMENT AND ANALYSIS OF DATA}

The BMDP statistical software on a VAX mainframe computer was used for management and analysis of data. Crude prevalence of outcomes that assumed a binomial probability distribution for men, for women, for standing, for sitting, and for mixed work were calculated. Multiple logistic regression techniques were used to explore various explanatory models of exposure and confounding variables for pain at various anatomical sites.

\section{Results}

The sample $(n=401)$ comprised 207 women and 194 men. Standing workers $(\mathrm{n}=$ $225)$, mixed workers $(n=105)$, and seated 
workers $(n=71$ ) were included. Response rate was $100 \%$. Table 1 presents participants by sex and industry.

Table 2 shows the prevalence of regional musculoskeletal pain for the sample overall. Prevalence of regional pain was grouped by sex and type of work (table 3 ) and grouped by industry (table 4). The prevalence of pain in

Table 3 Prevalence of regional musculoskeletal pain grouped by sex and type of work (standing, seated, and mixed work)

\begin{tabular}{llll}
\hline & $\begin{array}{l}\text { Neck and shoulder } \\
(95 \% C I)\end{array}$ & $\begin{array}{l}\text { Back } \\
(95 \% C I)\end{array}$ & $\begin{array}{l}\text { Forearm, wrist } \\
\text { and hand } \\
(95 \% C I)\end{array}$ \\
\hline $\begin{array}{l}\text { Seated men } \\
(\mathrm{n}=16)\end{array}$ & $0.13(0.000$ to 0.294$)$ & $0.13(0.000$ to 0.294$)$ & $0.06(0.015$ to 0.105$)$ \\
$\begin{array}{l}\text { Seated women } \\
(\mathrm{n}=55)\end{array}$ & $0.31(0.188$ to 0.432$)$ & $0.23(0.118$ to 0.341$)$ & $0.02(0.009$ to 0.031$)$ \\
$\begin{array}{l}\text { Mixed men } \\
(\mathrm{n}=83)\end{array}$ & $0.09(0.028$ to 0.152$)$ & $0.22(0.131$ to 0.309$)$ & $0.00(0.000$ to 0.000$)$ \\
$\begin{array}{l}\text { Mixed women } \\
(\mathrm{n}=22)\end{array}$ & $0.09(0.000$ to 0.210$)$ & $0.22(0.047$ to 0.393$)$ & $0.00(0.000$ to 0.000$)$ \\
$\begin{array}{l}\text { Standing men } \\
(\mathrm{n}=95)\end{array}$ & $0.08(0.025$ to 0.135$)$ & $0.13(0.068$ to 0.198$)$ & $0.02(0.000$ to 0.048$)$ \\
$\begin{array}{l}\text { Standing women } \\
(\mathrm{n}=130)\end{array}$ & $0.16(0.097$ to 0.223$)$ & $0.22(0.149$ to 0.291$)$ & $0.04(0.006$ to 0.074$)$ \\
\hline
\end{tabular}

Table 4 Prevalence of regional musculoskeletal pain grouped by industry

\begin{tabular}{|c|c|c|c|}
\hline & $\begin{array}{l}\text { Neck and shoulder } \\
(95 \% \text { CI })\end{array}$ & $\begin{array}{l}\text { Back } \\
(95 \% \text { CI) }\end{array}$ & $\begin{array}{l}\text { Forearm, wrist } \\
\text { and hand } \\
(95 \% \mathrm{CI})\end{array}$ \\
\hline $\begin{array}{l}\text { Motor vehicle } \\
\text { assembly }(n=68) \\
\text { Pharmaceutical } \\
\text { products }(n=28) \\
\text { Metal products } \\
(n=19) \\
\text { Chicken processing } \\
\text { (n= 40) } \\
\text { Fruit packing } \\
(n=42) \\
\text { Nylon spinners } \\
\text { (n=27) } \\
\text { Dog and baby food } \\
\text { (n= 31) } \\
\text { Potato crisp factory } \\
\text { (n=38) } \\
\text { Clothing } \\
\text { factory } 1 \text { ( } n=19) \\
\text { Clothing } \\
\text { factory } 2 \text { ( } n=42) \\
\text { Canning factory } \\
\text { (n=47) }\end{array}$ & $\begin{array}{l}0.21 \\
(0.113 \text { to } 0.307) \\
0.11 \\
(0.000 \text { to } 0.226) \\
0.00 \\
(0.000 \text { to } 0.000) \\
0.13 \\
(0.026 \text { to } 0.234) \\
0.21 \\
(0.202 \text { to } 0.218) \\
0.07 \\
(0.000 \text { to } 0.166) \\
0.07 \\
(0.000 \text { to } 0.160) \\
0.13 \\
(0.023 \text { to } 0.237) \\
0.02 \\
(0.002 \text { to } 0.038) \\
0.21 \\
(0.087 \text { to } 0.333) \\
0.13 \\
(0.034 \text { to } 0.226)\end{array}$ & $\begin{array}{l}0.21 \\
(0.113 \text { to } 0.307) \\
0.25 \\
(0.090 \text { to } 0.410) \\
0.26 \\
(0.063 \text { to } 0.457) \\
0.39 \\
(0.238 \text { to } 0.541) \\
0.07 \\
(0.000 \text { to } 0.147) \\
0 \cdot 11 \\
(0.000 \text { to } 0.228) \\
0.26 \\
(0.106 \text { to } 0.414) \\
0 \cdot 24 \\
(0.104 \text { to } 0.376) \\
0 \cdot 29 \\
(0.009 \text { to } 0.494) \\
0.10 \\
(0.009 \text { to } 0.191) \\
0.17 \\
(0.063 \text { to } 0.277)\end{array}$ & $\begin{array}{l}0.03 \\
(0.011 \text { to } 0.070) \\
0.00 \\
(0.000 \text { to } 0.000) \\
0.00 \\
(0.000 \text { to } 0.000) \\
0.05 \\
(0.000 \text { to } 0.117) \\
0.00 \\
(0.000 \text { to } 0.000) \\
0.03 \\
(0.000 \text { to } 0.094) \\
0.00 \\
(0.000 \text { to } 0.000) \\
0.03 \\
(0.000 \text { to } 0.094) \\
0.00 \\
(0.000 \text { to } 0.000) \\
0.00 \\
(0.000 \text { to } 0.000) \\
0.02 \\
(0.000 \text { to } 0.060)\end{array}$ \\
\hline
\end{tabular}

the neck and shoulders ranged from 0.00 to 0.21 (95\% confidence interval (95\% CI) 0.202 to 0.218 ) between industries with an overall prevalence of 0.14 (95\% CI 0.106 to $0 \cdot 174)$. The highest prevalences were found in the motor assembly, fruit packing, and clothing industries. Pain of the lower back was a ubiquitous phenomenon, with an overal prevalence of $0.20(95 \%$ CI 0.161 to 0.207$)$, no industry was exempt, the prevalence ranged from 0.07 (95\% CI 0.000 to 0.147 ) to 0.39 (95\% CI 0.238 to 0.541$)$. The chicken processing and clothing factories had the highest prevalence of pain in the lower back. The prevalence of pain in the forearms, wrists, and hands was 0.02 (95\% CI 0.006 to 0.034$)$ for acute pain and $0.04(95 \% \mathrm{CI} 0.021$ to $0.059)$ for chronic pain. Prevalence ranged between occupations from 0 to 0.05 (95\% CI 0.000 to 0.117$)$ for acute and 0 to $0.10(95 \%$ CI 0.014 to 0.186 ) for chronic pain. The highest prevalence was found in the fruit packing and canning industries.

Women had a higher prevalence of regiónal pain than their male counterparts in seated, mixed, and standing work with the exception of pain in the forearms, wrists, and hands in seated work, where men scored higher (table 3).

Exposures were described with a profile of scores on various dimensions of ergonomic stressors. Mean exposure scores and frequency of categorical exposure variables differed by industry (table 5 ).

Multiple logistic regression analysis yielded similar patterns of predictors of regional pain as previously reported. ${ }^{1}$ Workplace ergonomic stressors showed significant associations with pain of the neck and shoulders but not with pain of the lower back. Further, in the present study, analysis of pain of the wrists and hands, which was not able to be reported previously due to insufficient numbers, yielded significant associations with ergonomic stressors to the wrists and hands. With a specific model for pain of the neck and shoulders, this study

Table 5 Mean exposure scores and frequency of categorial exposure by industry

\begin{tabular}{|c|c|c|c|c|c|c|c|c|c|c|c|}
\hline & \multirow[b]{2}{*}{$\begin{array}{l}\text { Force } \\
\text { mean }(S D)\end{array}$} & \multirow[b]{2}{*}{$\begin{array}{l}\text { Traps } \\
\text { mean (SD) }\end{array}$} & \multirow[b]{2}{*}{$\begin{array}{l}\text { Trapd } \\
\text { mean }(S D)\end{array}$} & \multirow[b]{2}{*}{$\begin{array}{l}\text { Backs } \\
\text { mean (SD) }\end{array}$} & \multirow[b]{2}{*}{$\begin{array}{l}\text { Backd } \\
\text { mean (SD) }\end{array}$} & \multirow[b]{2}{*}{$\begin{array}{l}\text { Wrists } \\
\text { mean (SD) }\end{array}$} & \multirow[b]{2}{*}{$\begin{array}{l}\text { Wristd } \\
\text { mean (SD) }\end{array}$} & \multicolumn{4}{|l|}{ Repetition } \\
\hline & & & & & & & & $\begin{array}{l}1 \\
n(\%)\end{array}$ & $\begin{array}{l}2 \\
n(\%)\end{array}$ & $\begin{array}{l}3 \\
n(\%)\end{array}$ & $\begin{array}{l}4 \\
n(\%)\end{array}$ \\
\hline $\begin{array}{l}\text { Motor vehicle } \\
\text { assembly }\end{array}$ & $0.00(0.05)$ & $12.5(3.73)$ & $1.32(1.72)$ & $2.57(1 \cdot 12)$ & $2.35(2.14)$ & $2.59(1.86)$ & $0.27(0.68)$ & $47(69)$ & $0(0)$ & $21(31)$ & $0(0)$ \\
\hline products & $3.61(1.29)$ & $12 \cdot 1(7 \cdot 45)$ & $0.43(0.50)$ & $2.57(3.81)$ & $0.43(0.50)$ & $0.00(0.00)$ & $0.00(0.00)$ & $16(57)$ & $12(43)$ & $0(0)$ & $0(0)$ \\
\hline Metal products & $5.00(2.67)$ & $3.00(1 \cdot 12)$ & $0.00(0.00)$ & $3.00(1.67)$ & $0.00(0.00)$ & $0.00(0.00)$ & $0.00(0.00)$ & $19(100)$ & $0(0)$ & $9(0)$ & $0(0)$ \\
\hline Chicken processing & $2 \cdot 35(1 \cdot 23)$ & $9 \cdot 20(3.67)$ & $2 \cdot 78(2 \cdot 14)$ & $3 \cdot 15(2 \cdot 58)$ & $3 \cdot 70(1 \cdot 47)$ & $0.00(0.00)$ & $3.40(3.39)$ & $14(35)$ & $10(25)$ & $0(0)$ & $16(40)$ \\
\hline Fruit packing & $2 \cdot 43(1 \cdot 48)$ & $7.43(6.09)$ & $6 \cdot 60(4 \cdot 63)$ & $2 \cdot 19(1 \cdot 70)$ & $1.62(2.00)$ & $0.00(0.00)$ & $6 \cdot 60(7 \cdot 52)$ & $42(100)$ & $0(0)$ & $0(0)$ & $0(0)$ \\
\hline Nylon spinners & $2.63(1.39)$ & $0.29(1.07)$ & $6.67(9.61)$ & $0.89(1.69)$ & $9 \cdot 22(8.84)$ & $0.00(0.00)$ & $0.00(0.00)$ & $27(100)$ & $0(0)$ & $0(0)$ & $0(0)$ \\
\hline Baby and dog food & $3.68(1.28)$ & $3.93(7.49)$ & $0.00(0.00)$ & $5 \cdot 61(3.18)$ & $0.00(0.00)$ & $0.00(0.00)$ & $0.00(0.00)$ & $22(71)$ & $0(0)$ & $9(29)$ & $0(0)$ \\
\hline Potato crisp factory & $1.42(1.24)$ & $3.90(2.55)$ & $0.00(0.00)$ & $4 \cdot 26(3.58)$ & $1.87(1.87)$ & $0.42(0.50)$ & $0.61(0.50)$ & $15(40)$ & $0(0)$ & $0(0)$ & $23(60)$ \\
\hline Clotby a factory 1 & $1.94(1.75)$ & $8.36(3.06)$ & $0.00(0.00)$ & $1.76(2 \cdot 19)$ & $3.06(1.75)$ & $0.47(0.87)$ & $0.77(0.44)$ & $37(77)$ & $0(0)$ & $11(23)$ & $0(0)$ \\
\hline ctory 2 & $2 \cdot 21(1 \cdot 76)$ & $8.36(3.06)$ & $0.00(0.00)$ & $3.07(1.70)$ & $1.05(1.78)$ & $0.57(0.83)$ & $0.41(0.73)$ & $42(100)$ & $0(0)$ & $0(0)$ & $0(0)$ \\
\hline $\mathbf{v}$ & $3.60(2.72)$ & $2.13(3.83)$ & $0.00(0.00)$ & $2.92(1.70)$ & $0.00(0.00)$ & $0.00(0.00)$ & $0.19(0.73)$ & $37(77)$ & $0(0)$ & $11(23)$ & $0(0)$ \\
\hline
\end{tabular}


Table 6 Logistic regression of pain in the neck and shoulder $(N=401, n=76)$

\begin{tabular}{|c|c|c|c|c|}
\hline & $\beta(S E M)$ & $\beta / S E M$ & $P$ value & OR $(95 \% C I)$ \\
\hline $\begin{array}{l}\text { TST (1) } \\
\text { Height } \\
\text { REP (1) } \\
\text { REP (3) }\end{array}$ & $\begin{array}{r}1.362(0.64) \\
-0.453(0.02) \\
1.683(0.78) \\
1.571(0.51)\end{array}$ & $\begin{array}{r}2 \cdot 14 \\
-2 \cdot 18 \\
2 \cdot 16 \\
3 \cdot 11\end{array}$ & $\begin{array}{l}0.032 \\
0.985 \\
0.031 \\
0.002\end{array}$ & $\begin{array}{l}3.91(1.11 \text { to } 13.7) \\
0.96(0.92 \text { to } 0.99) \\
5.38(1.16 \text { to } 25.0) \\
4.81(1.78 \text { to } 13.0)\end{array}$ \\
\hline
\end{tabular}

Adjusted for sex, age, and height. Also included in the model (but did not reach significance) were whole body force, neck and shoulder and wrist postures (static and dynamics), and length of service in current job. TST (I) = seated compared with standing work, REP (1) = medium compared with low level of repetitiveness; REP (3) very high compared with low level of repetitiveness.

Table 7 Logistic regression of pain in the forearm, wrist, and hand $(N=401)(n=15)$

\begin{tabular}{lrrll}
\hline & $\beta(S E M)$ & $\beta / S E M$ & $P$ value & OR (95\% CI) \\
\hline Sex & $-2.148(1.07)$ & -2.00 & 0.046 & $0.12(0.01$ to 0.95$)$ \\
Wrist & $2.327(1.02)$ & 2.28 & 0.023 & $10.2(1.39$ to 75.6$)$ \\
\hline
\end{tabular}

Included in the model (but did not reach significance) were: TST (1) (seated compared with standing work), TST (2) (mixed compared with standing work), neck and shoulder postures (static and dynamics), static wrist postures, age, high mental concentration demands, cold temperature, repetition, and length of service in the current job.

indicated that repetitive work, seated rather than standing work, and height (being short) were significantly associated with pain of the neck and shoulder (table 6). None of the workplace ergonomic factors were significantly associated with pain of the lower back; the only variable that emerged as significant in the regression analysis on back pain was sex (being a woman) $(\beta 1.014$; SEM $0.47 ; \beta /$ SEM $2 \cdot 18 ; \mathrm{P} 0.029$; odds ratio (OR) $2 \cdot 76 ; 95 \% \mathrm{CI}$ $1 \cdot 10$ to $6 \cdot 88$ ). For pain of the wrists and hands, sex (being a man) and wristd (a summed score of dynamic postures of the wrist and hand) were significant contributors to pain (table 7). There were no statistical interactions between exposure and other covariables, or between the main dimensions of exposure (force, posture, and repetition).

\section{Discussion}

This study was able to show a clear work related excess of regional musculoskeletal pain linked to ergonomic exposures. The observed high background prevalence of musculoskeletal pain was expected. This concurred with the existing scientific literature. Findings in this study for pain of the lower back, but not for other regional pain, concur with the well documented sex difference in reporting pain, where women tend to report more pain than men. The prevalence of pain of the forearms, wrists and hands in this study was lower than expected, particularly as anecdotally, disorders of the hands and wrists were regarded as a major problem by some personnel and workers in the factories' clinics. The reason this was not reflected in the data on prevalence may be partially explained by an aspect of the healthy worker effect in which workers with symptoms of the hands and wrists are disabled for their jobs. None the less a work related excess was evident for symptoms of the forearms, wrists, and hands (table 7). A work related excess was also evident for pain of the neck and shoulders (table
6), but not for pain of the lower back, which is not surprising given its multiple aetiology.

Subjective reports of musculoskeletal pain with no attempt at diagnosis was considered to be the most appropriate measure of outcome in this study. These measures have high generality, they are easy to use in the field and are of proved validity. ${ }^{7}$ Measures of self reported pain seem to have less credibility than clinical measures overall-for example, studies excluded from Stock's review. ${ }^{3}$ This may be at least partially due to the controversy surrounding the existence of workrelated musculoskeletal disorders, ${ }^{7}$ where "harder" outcomes were perhaps perceived to be more credible. A simple outcome measure is arguably less sensitive to misclassification of outcome than complex clinical diagnostic entities, given inconsistent case criteria and lack of usefulness in the field of many of these diagnoses..$^{10}$ Also, musculoskeletal symptoms often present atypically, and the use of only a few discrete symptom patterns according to diagnostic criteria, would exclude many adverse musculoskeletal outcomes from study; such studies may underestimate exposure-effect relations, particularly as damage to one structure may evoke damage to interconnected structures.

Although we think that this study represents a considerable improvement in characterisation of exposure relative to previous work, non-differential misclassification of exposure may have arisen in this study in various ways and contributed to an attenuation of strength of association with musculoskeletal pain. Firstly, the assumption of homogeneity of exposure in a single job category is a potential source of misclassification of exposure, the extent of which is dependent on the relation between variation between people and jobs. ${ }^{11}$ It was not feasible in this study to specifically assess the extent of variation between people within each exposure zone. This would have necessitated a separate study for each of the 46 exposure zones across each dimension of exposure. To facilitate a low variation between people in this study, exposure zones were selected on the basis of strict inclusion criteria as already described. None the less, postural items, more so than repetitiveness or whole body force may vary considerably between people in the same job, due to differences in work technique or anthropometry. The lack of association between the regional postural scores and pain of the neck and shoulders may simply be due to a lack of effect, or may arise from a lack of homogeneity between workers in the same job on this aspect of exposure.

Possible invalid aspects of the model may also have given rise to misclassification of exposure, but the process of full validation of such a model is hindered by the poorly understood pathogenesis of musculoskeletal disorders and the interaction between ergonomic factors and other extraneous factors. The publications on ergonomics are full of laboratory evidence that links adverse postures, force, and repetition to acute effects such as 
discomfort. Whether or not these effects are precursors of musculoskeletal disorders is unclear, and not yet proved.

A research area indicated by this study is the development of finer measures (of greater generality, capacity, and sensitivity) for dimensions of exposure considered important in the scientific literature where there is disagreement or haziness of meaning. The term "postural constraint" is a case in point; ergonomists would generally agree that being unable to adopt a variety of postures is undesirable, but how to quantify this lack of flexibility is less clear. Measures of the frequency of transitions between sitting and standing have been used to describe constraint, but are not very helpful for the many industrial jobs in which workers have to be sitting or standing all of the time. Another problematic dimension of exposure is force, the use of a psychophysical rating scale allows for the measurement of whole body force, but regionally specific forces, relevant in surveys that include disorders of the hands and wrists, are more difficult to include in a simple low technology model. Lastly, the development of an appropriate measure of outcome and its link to work related musculoskeletal disorders is required; self reported pain promises the appropriate outcome measure that is required, but the range of disorders need to have better defined nodes and endpoints for further study.

1 Schierhout GH, Myers JE, Bridger RS. Musculoskeletal pain and workplace ergonomic stressors in manufactur ing industry in South Africa. International fournal of Industrial Ergonomics 1993;12:3-11

2 Burdorf A. Exposure assessment of risk factors for disor ders of the back in occupational epidemiology. Scand $f$ Work Environ Health 1992;18:1-9.

3 Stock SR. Workplace ergonomic factors and the develop ment of musculoskeletal disorders of the neck and uppe
limbs: a meta-analysis. Am f Ind Med 1991;19:87-107.

4 Schierhout GH, Bridger RS, Myers JE. The development of observational methods for the estimations of exposure to workplace postural stressors. Occup Med 1995 (in press).

5 Leidel NA, Busch KA, Lynch JR. Occupational exposure sampling strategy manual. Cincinnati: National Institut for Occupational Safety and Health. US Department of Health, Education and Welfare, Public Health Service, Health, Education and Welfare, Public Hea

6 Silverstein BA, Fine LJ, Armstrong TJ. Hand wrist cumulative trauma disorders in industry. $\mathrm{Br} \mathcal{f}$ Ind $\mathrm{Med}$ -
laterstein $\mathrm{BA}$, Fine LJ, Armstrong TJ. Hand wrist cumulative trauma di

7 Chiang H, Ko Yin Ching, Chen Shun-Shenb, Yu Hsin$\mathrm{Su}$, Wu Trong-Neng, Chang Po-Ya. Prevalence of shoulder and upper limb disorders among workers in th fish-processing industry. Scand $\mathcal{f}$ Work Environ Health 1993;19:126-31

8 Hadler NM. Cumulative trauma disorders. An iatrogeni concept. F Occup Med 1990;32:38-41.

9 Katz JN, Larson MG, Sabra A, Krarup C, Stirrat CR Sethi $R$, et al. The carpel tunnel syndrome: diagnostic utility of the history and physical examination findings. Ann Intern Med 1990;112:321-7.

10 Cuetter AC, Bartosek DM. The thoracic outlet syndrome controversies, overdiagnosis, overtreatment and recom mentations for management. Muscle Nerve 1989;12:410

11 Burdorf A. Sources of variance in exposure to postura load on the back in occupational groups. Scand $\mathcal{F}$ Work Environ Health 1992;18:361-7.

\section{Rejected manuscripts}

From February 1994, authors whose submitted articles are rejected will be advised of the decision and one copy of the article, together with any reviewers' comments, will be returned to them. The fournal will destroy remaining copies of the article but correspondence and reviewers' comments will be kept. 